\title{
Special features and issues
}

\author{
Takashi Saitoh
}

Published online: 5 December 2009

(C) The Society of Population Ecology and Springer 2009

\section{Introduction}

In the previous volume (vol 51, 2009), Population Ecology has published one special feature entitled "Community in a marine system" with five papers (Doi 2009; Kadoya 2009; Noda 2009; Pineda et al. 2009; Yamakita and Nakaoka 2009) and one special issue about the Allee effect that consisted of nine papers (Boukal and Berec 2009; Fauvergue and Hopper 2009; Gascoigne et al. 2009; Kramer et al. 2009; Sato 2009; Takasu 2009; Takimoto 2009; Tobin et al. 2009; Yamanaka and Liebhold 2009). Special Features (SF) are usually comprised of 4-8 papers led by a short Introduction. SF articles need not represent totally original work on the part of the authors, but instead can review or synthesize a body of work. If the volume of collected articles is large enough, an entire special issue, comprised of only those articles, would be considered. We are encouraging researchers to propose a plan for a SF (see "SF instruction" on our website: http://www.springer.com/10144).

Groups of papers published as special features have been assembled from two sources: symposia organized by the Society of Population Ecology and proposals from researchers. Here, we would like to stress that proposals for special features are open to all scientists. We welcome any proposals that appeal to the broad interest of ecologists. Submitted proposals will be reviewed by the editorial office (the chief editor and associate editors) based on comments from board members. See the website (http:// www.springer.com/10144) for detailed information.

T. Saitoh $(\bowtie)$

Field Science Center, Hokkaido University,

North 11, West 10, Sapporo 060-0811, Japan

e-mail: tsaitoh@fsc.hokudai.ac.jp
Even if a proposal is judged to be appropriate for the journal, this does not mean that all papers in the section will necessarily be accepted for publication. All papers must go through the journal's normal, rigorous review process. It is critical that the organizers and the authors all recognize that some component papers may be rejected or substantial revision may be required.

\section{Editorial statistics}

During 2008, a total of 134 manuscripts were submitted from authors located in 34 different countries. Totals of $37(27.6 \%)$ and $34(25.4 \%)$ manuscripts originated from Europe and Japan, respectively (Fig. 1). Although there were a considerable number of submissions from Asian countries other than Japan $(25 ; 18.7 \%)$, their representation in accepted papers was limited $(6.5 \%)$. The rate of acceptance was $36.0 \%$ for non-invited papers excluding manuscripts for special features. The rate of acceptance of manuscripts from Europe $(35.1 \%)$ was close to the average, while those from Japan, North America, and Oceania were higher than the average.

The average time $( \pm$ SD) between the receipt of a manuscript and return of the first report to authors was 47.4 days $( \pm 32.1)$. The first round of review for 93 manuscripts $(69.4 \%)$ was completed within 60 days (Fig. 2), while the number of manuscripts for which the first round of review was finished within 90 days was 122 (91.0\%). The average editorial time for manuscripts that were rejected was shorter than for those where revision was requested; 23 manuscripts were rejected by the editor before sending them to reviewers. We are encouraging handling editors and reviewers to review manuscripts faster and, as a goal in 2010, we intend that the first round of 


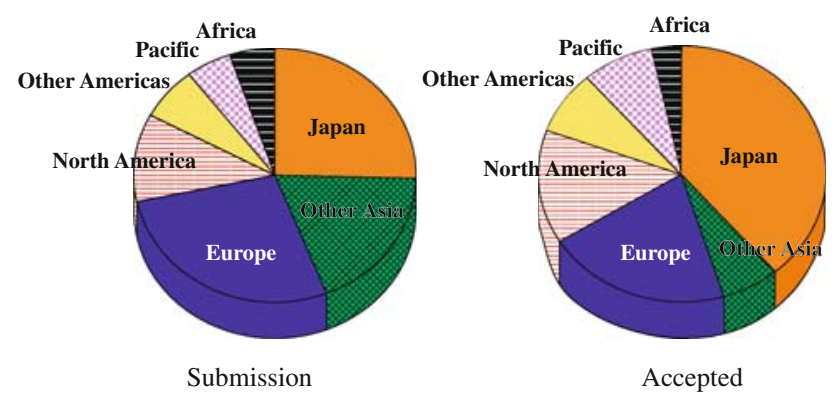

Fig. 1 Regional proportions of submissions (left: $n=134$ ) and accepted manuscripts (right: $n=61$ )

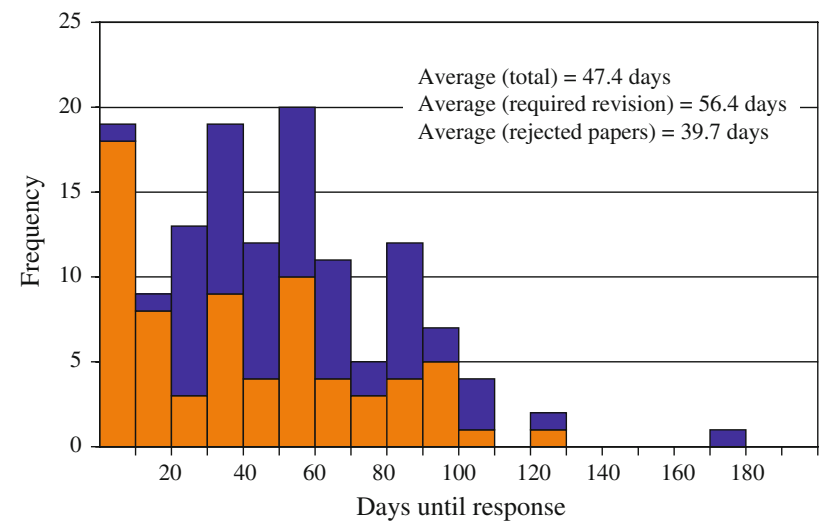

Fig. 2 Frequency distribution of the average editorial time between the receipt of a manuscript and return of the first report to authors. Light shaded (orange) bars: frequencies for manuscripts rejected at the first round of the review; dark shaded (blue) bars: those for manuscripts that required revision

review for $80 \%$ of manuscripts would be completed within 60 days.

The number of submissions has increased considerably since 2001 (Fig. 3). Because the rate of submissions from Japan has remained relatively stable, the increase of submissions can be attributed to increases from other countries. Population Ecology's impact factor, reported by ISI, has dramatically increased during the most recent 10 years and has nearly reached 2.0 (Fig. 3).

\section{Colored figures in online versions}

Inclusion of color figure(s) in papers published in Population Ecology has generally required that the author(s) cover the cost of color printing. However, online versions of accepted manuscripts can be now be edited in color at no cost, as long as the same figure appears in monochrome in the printed version. For example, this editorial is edited in color as an online version but will be printed in monochrome.

When an online version, edited in color, is used for the print version in monochrome, the contrast of figures may

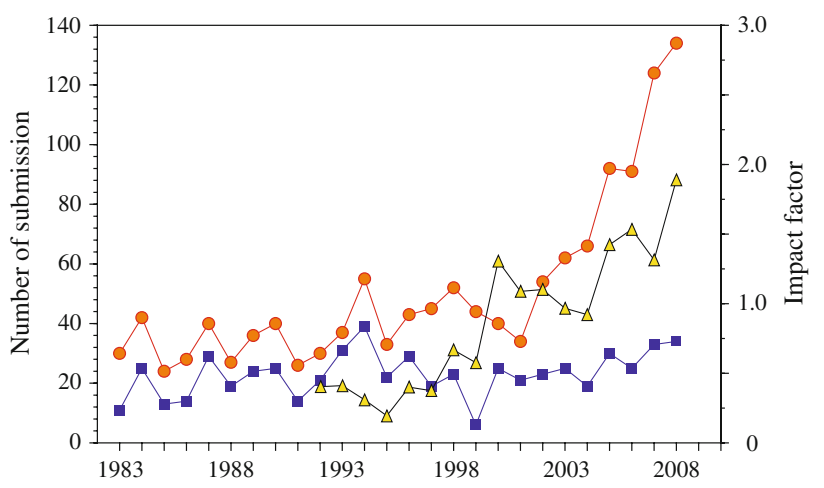

Fig. 3 Changes in the number of submissions in total (circle), that from Japan (square), and the impact factor (triangle)

reproduce poorly in the latter form. To avoid this problem, the author(s) should carefully prepare figures taking effective contrast into consideration. Blue, orange, and yellow are distinguishable, when they are transformed to gray scale, but it is very difficult to distinguish gray scale versions that are originally composed of red and blue or green and yellow. However, the colors and patterns illustrated in Fig. 1 are effective for both color and monochrome versions. In cases where more than three colors and patterns are used, the author(s) should show the corresponding relationship as in Fig. 1. When color patterns are simple, the author(s) can explain the corresponding relationship in the text of the figure caption (see Fig. 2).

When a chart consists of several lines, colors are helpful to distinguish the lines (Fig. 3). Although the contrast between the lines becomes less clear in gray scale, they can be distinguished by symbols.

As illustrated in the three figures accompanying this article, colors are helpful for understanding the contents of figures. We encourage authors to use colors in the online version. However, please prepare figures carefully, taking contrast into consideration.

\section{Photos on the cover page}

Two photos have been selected from articles published in 2009 and the other two from this issue.

The photograph on the lower right is of a tiger called the Ganga male, residing in a riverine patch that forms a vital link between forests across the river Ganga (Harihar et al. 2009). The river Ganga $(2,500 \mathrm{~km})$ is one of the major rivers in the Indian Subcontinent, and while most of the forests along the banks of the Ganges have been lost owing to developmental activities, this stretch of forest spanning $7 \mathrm{~km}$ within the Rajaji National Park, Uttrakhand, India, is probably the last remaining riverine forest still supporting populations of large mammals such as tigers and elephants. 
Helianthemum squamatum is an erect dwarf chamaephyte growing in gypsum outcrops at lower elevations in the Iberian Peninsula (upper left). Quintana-Ascencio et al. (2009) assessed the role of microhabitat spatial structure on its demography using a cellular automaton model. Their simulations suggest the potential effect of grazing and open interesting questions for future research.

A gape-limited pedatory salamander larva (Hynobius retardatus) consuming a Rana pirica frog tadpole was photographed by Takuya Ikawa (upper right). In this predator-prey interaction, both predator and prey species exhibit dramatic morphological changes to adapt their antagonistic relationship. Kishida et al. (2010) review recent advances in evolutionary ecology of morphological plasticity in predator and prey.

A female parasitoid, Anisopteromalus carandrae, is ovipositing on host larvae inside a bean (lower left). They learned olfactory cues by previous experience and showed biased searching behavior for the experienced host. Many parasitoid species are well known to learn and flexibly modify their host searching behavior, influencing the hostparasitoid population dynamics (Ishii and Shimada 2010).

\section{References}

Boukal DS, Berec L (2009) Modelling mate-finding Allee effects and populations dynamics, with applications in pest control. Popul Ecol 51:445-458

Doi H (2009) Spatial patterns of autochthonous and allochthonous resources in aquatic food webs. Popul Ecol 51:57-64

Fauvergue X, Hopper KR (2009) French wasps in the New World: experimental biological control introductions reveal a demographic Allee effect. Popul Ecol 51:385-397

Gascoigne J, Berec L, Gregory S, Courchamp F (2009) Dangerously few liaisons: a review of mate-finding Allee effects. Popul Ecol 51:355-372
Harihar A, Pandav B, Goyal SP (2009) Subsampling photographic capture-recapture data of tigers (Panthera tigris) to minimize closure violation and improve estimate precision: a case study. Popul Ecol 51:471-479

Ishii Y, Shimada M (2010) The effect of learning and search images on predator-prey interactions. Popul Ecol 52:27-35

Kadoya T (2009) Assessing functional connectivity using empirical data. Popul Ecol 51:5-15

Kishida O, Trussell GC, Mougi A, Nishimura K (2010) Evolutionary ecology of inducible morphological plasticity in predator-prey interaction: toward the practical links with population ecology. Popul Ecol 52:37-46

Kramer AM, Dennis B, Liebhold AM, Drake JM (2009) The evidence for Allee effects. Popul Ecol 51:341-354

Noda T (2009) Metacommunity-level coexistence mechanisms in rocky intertidal sessile assemblages based on a new empirical synthesis. Popul Ecol 51:41-55

Pineda J, Reyns N, Starczak VR (2009) Complexity and simplification in understanding recruitment in benthic populations. Popul Ecol 51:17-32

Quintana-Ascencio PF, Caballero I, Olano JM, Escudero A, Albert MJ (2009) Does habitat structure matter? Spatially explicit population modeling of an Iberian gypsum endemic. Popul Ecol 51:317-328

Sato K (2009) Allee threshold and extinction threshold for spatially explicit metapopulation dynamics with Allee effects. Popul Ecol 51:411-418

Takasu F (2009) Individual-based modeling of the spread of pine wilt disease: vector beetle dispersal and the Allee effect. Popul Ecol 51:399-409

Takimoto G (2009) Early warning signals of demographic regime shifts in invading populations. Popul Ecol 51:419-426

Tobin PC, Robinet C, Johnson DM, Whitmire SL, Bjørnstad ON, Liebhold AM (2009) The role of Allee effects in gypsy moth, Lymantria dispar (L.), invasions. Popul Ecol 51:373-384

Yamakita T, Nakaoka M (2009) Scale dependency in seagrass dynamics: how does the neighboring effect vary with grain of observation? Popul Ecol 51:33-40

Yamanaka T, Liebhold AM (2009) Spatially implicit approaches to understand the manipulation of mating success for insect invasion management. Popul Ecol 51:427-444 